\title{
Direito fundamental à educação, diversidade e homofobia na escola: desafios à construção de um ambiente de aprendizado livre, plural e democrático
}

\section{The fundamental right to education, diversity and homophobia in school: the challenges to build a free, plural and democratic learning environment scenario}

\author{
Graziela Raupp Pereira ${ }^{1}$ \\ Alexandre Gustavo Melo Franco Bahia ${ }^{2}$
}

\begin{abstract}
RESUMO
A educação é um direito fundamental garantido internacional e nacionalmente. Para construir uma sociedade democrática e livre de preconceitos, há de se garantir o acesso à educação, mas que esta se desenvolva como espaço de cidadania, liberdade e diversidade.

Palavras-chave: educação; homofobia; direitos fundamentais; educação sexual intencional.
\end{abstract}

1 Doutora realizando Pós-doutorado, atualmente é docente na Universidade de Aveiro, em Portugal.

2 Possui graduação em Direito pela Universidade Federal de Minas Gerais (2001), Mestrado em Direito Constitucional pela Universidade Federal de Minas Gerais (2004) e Doutorado em Direito Constitucional pela Universidade Federal de Minas Gerais (2007). Atualmente é membro do corpo permanente do curso de Mestrado da Faculdade de Direito do Sul de Minas; professor adjunto da Faculdade de Direito do Sul de Minas e professor assistente do Instituto Metodista Izabela Hendrix e Faculdade de Minas Gerais (FAMIG), Brasil. 


\begin{abstract}
Education is both internationally and nationally granted as a fundamental right. In order to build a democratic and unbiased society, it's necessary to warrant the access to education, yet the latter must develop itself as an environment of citizenship, freedom and diversity.

Keywords: education; homophobia; fundamental rigths; intentional sexual education.
\end{abstract}

\title{
Introdução
}

A consolidação dos ideais de pluralidade nas sociedades ocidentais parece ter levado a movimentos de emancipação de grupos minoritários, excluídos e marginalizados, e à ruptura gradual com estruturas ou instituições sociais que preservam hierarquias, intolerância e segregação. Segundo Piovesan (2009, p. 295-296):

Ao longo da história as mais graves violações aos direitos humanos tiveram como fundamento a dicotomia do "eu" versus o "outro", em que a diversidade era captda como elemento para aniquilar direitos. Vale dizer, a diferença era visibilizada para conceber o "outro" como um ser menor em dignidade e direitos, ou, em situações-limite, um ser esvaziado mesmo de qualquer dignidade, um ser descartável [...]. Nesta direção merecem destaque as violações da escravidão, do nazismo, do sexismo, do racismo, da homofobia, da xenofobia e de outras práticas de intolerância.

A escola precisa contribuir com esse movimento de emancipação, de tornar a diversidade sexual algo discutido, conversado com tranquilidade, para que o ser humano possa relacionar-se melhor com ele próprio e com os outros. Nos tempos hodiernos, é pensamento corrente que para se viver democraticamente em uma sociedade plural é preciso respeitar os diferentes grupos e culturas que a constituem.

Nessa mesma linha de pensamento, Garrido, Pimenta e Moura (2000, p. 92) afirmam que as organizações escolares são "produtoras de práticas sociais, de valores, de crenças e de conhecimentos, movidas pelo esforço de procurar novas soluções para os problemas vivenciados". 
Diante dessa realidade, ganham igual importância as dinâmicas resultantes da prática do professor, seja em que disciplina for, tanto nas Ciências Humanas, quanto em outras áreas mais técnicas, implicando no entendimento e decisão sobre a resolução de diversos problemas. Estes, certamente, sempre dizem respeito às circunstâncias da organização do sistema de ensino, às carências pessoais dos educandos, bem como às suas relações sociais e políticas. Fato que tem demandado dos educadores a busca de aperfeiçoamento no seu agir profissional e de ampliação do seu conhecimento, assim como uma reflexão aprofundada nas revisões das políticas e práticas educativas de inúmeros países.

Assim, continuam atuais os desafios à escola, postos pelo $\mathrm{PCN}$, em meados da década passada:

O grande desafio da escola é reconhecer a diversidade como parte inseparável da identidade nacional e dar a conhecer a riqueza representada por essa diversidade etnocultural que compõe o patrimônio sociocultural brasileiro, investindo na superação de qualquer tipo de discriminação e valorizando a trajetória particular dos grupos que compõem a sociedade. Nesse sentido, a escola deve ser local de aprendizagem de que as regras do espaço público permitem a coexistência, em igualdade, dos diferentes. (BRASIL, 1997a).

Se esta constatação for verdadeira, pode-se questionar que modelo de escola pretende-se criar em nosso país. Já se reconhece de forma quase consensual entre os educadores que a educação não deve ser feita, por exemplo, somente para alunos brancos, de classe média e cristãos (PRADO, 1984). Seguindo o mesmo raciocínio, parece pertinente o seguinte questionamento: porventura, deve o ensino ser direcionado única e exclusivamente para alunos heterossexuais? As singularidades dos alunos homossexuais são desprezíveis quando se propõe elaborar um ensino plural e multicultural que respeite valores cívicos e democráticos como a tolerância e o respeito às minorias?

Muito se tem discutido sobre as questões da diversidade cultural e suas consequências na educação em um país multicultural como o Brasil, que não possui uma lei específica para a Educação Sexual, não obstante as escolas brasileiras contarem, desde 1997, com a proposta inovadora dos Parâmetros Curriculares Nacionais (PCNs), criados pelo Ministério da Educação e do Desporto (MEC) e editados inicialmente em formato de livros. Este conjunto de documentos oficiais indica que os chamados "temas transversais", como por exemplo, a sexualidade, sejam trabalhados de forma integrada, contínua e sistemática, incorporados às áreas já existentes e ao trabalho educativo da escola: 
"tratam de processos que estão sendo intensamente vividos pela sociedade, pelas comunidades, pelas famílias, pelos alunos e educadores em seu cotidiano" (BRASIL, SEF, 1998, p. 26).

A própria Lei de Diretrizes e Bases da Educação Nacional, Lei nº 9394/96, prescreve em seu texto a defesa do "pluralismo de ideias e respeito às concepções pedagógicas" (Art. $3^{\circ}$, III). Porém, é nos PCNs, que fica mais evidenciado o termo pluralismo cultural como tema transversal (cf. infra), assegurando pela defesa da diversidade e dos excluídos socialmente, que se deve haver no Brasil a igualdade de oportunidades educacionais pata todos.

Percebe-se, no entanto, que o MEC ainda não possui um instrumento de avaliação de receptividade dessas propostas capaz de informar quantas escolas já possuem em seus currículos um registro explícito de debates, reflexões e projetos com o tema da educação sexual, apesar da constatação oficial de que os temas transversais permeiam sempre toda a prática educativa e estendem-se às diversas relações do espaço pedagógico, tenham consciência disso ou não os elementos da comunidade escolar.

A transversalidade pressupõe um tratamento integrado das áreas e um compromisso das relações interpessoais e sociais escolares com as questões que estão envolvidas nos temas, afim de que haja uma coerência entre os valores experimentados na vivência que a escola propicia aos alunos e o contato intelectual com tais valores. (BRASIL, SEF apud COSTA, 2001, p. 103).

Nessa perspectiva, é preciso uma reflexão sobre as rupturas construídas que ocorrem no currículo educacional, nas diferentes disciplinas, com vista à promoção de uma prática pedagógica que elimine o isolamento da atuação docente às atividades formais.

\section{O princípio da não discriminação na Constituição de 1988 e os Sistemas Nacional e Internacional de Proteção dos Direitos Fun- damentais}

Em um sistema constitucional que se apresenta como constante aprendizado, a Constituição é (e deve ser tida, sempre como) um projeto aberto 
a constantes novas inclusões. Isso possibilita que novos direitos possam ser incorporados, como, aliás, consta expressamente do parágrafo $2^{\circ}$ de seu artigo $5^{\circ}$ : "Os direitos e garantias expressos nesta Constituição não excluem outros decorrentes do regime e dos princípios por ela adotados, ou dos tratados internacionais em que a República Federativa do Brasil seja parte" (CARVALHO NETTO, 2004, p. 282).

No que tange a Tratados Internacionais (e similares) sobre Direitos Humanos de que o Brasil é signatário e que, de alguma forma, tratam da igualdade (bem como da proibição de discriminação), podemos citar: a Declaração Universal dos Direitos Humanos, de 1948, especialmente o Art. 2 ${ }^{\circ}$. "Toda pessoa tem capacidade para gozar os direitos e liberdades estabelecidos nesta Declaração, sem distinção de qualquer espécie, seja de raça, cor, sexo, língua, opinião, ou de outra natureza, origem nacional ou social, riqueza, nascimento ou qualquer outra condição"; o Pacto de San José da Costa Rica; e a Declaração sobre a Eliminação de Todas as Formas de Intolerância e Discriminação Fundadas na Religião ou nas Convicções (Resolução da ONU), de 1981.

A Organização Mundial da Saúde (OMS), já em 1975 deixava claro que a sexualidade (desde uma dimensão muito ampla e diversificada), inserida na temática da saúde, também é um direito humano (cf. BRASIL, 1997b).

Além desses instrumentos, há alguns que merecem especial atenção:

1) Resolução n 2435: Direitos Humanos, Orientação Sexual e Identidade de Gênero, aprovada pela Assembleia Geral da OEA em 03 de junho de 2008, mostrando preocupação com os "atos de violência e das violações aos direitos humanos correlatas perpetradas contra indivíduos, motivados pela orientação sexual e pela identidade de gênero"3.

2) Também em 2008 foi aprovada uma Declaração da ONU condenando violações dos direitos humanos com base na orientação sexual e na identidade de gênero. Na Declaração (A/63/635, de 22/12/08) os países signatários condenaram

as violações de direitos humanos baseadas na orientação sexual ou na identidade de gênero onde queira que tenha lugar [...]. Urgimos aos Estados a que tomem todas as medidas necessárias, em particular as legislativas ou administrativas, para assegurar que a orientação sexual ou identidade de gênero não possam ser, sob nenhuma circunstância, a base de sanções penais, em particular execuções, prisões ou detenção.

3 Identidade de Gênero diz respeito a quais papeis sociais de gênero o indivíduo se identifica (masculino, feminino ou transgênero); já a Orientação Sexual diz respeito a que sexo está voltado o desejo o afeto e o desejo sexual de alguém (daí se falar em heterossexual, homossexual e bissexual). (RIOS, 2001, p. 281). 
A despeito dos méritos da Resolução e da urgência na aprovação de atos internacionais vinculantes, é importante anotar que ainda não existe nenhuma Convenção Internacional sobre o tema.

De todos estes instrumentos internacionais o Brasil é participante, integrando aqueles a ordem jurídica interna (cf. arts. $3^{\circ}$, IV e $5^{\circ}$, caput e $\S \S 2^{\circ}$ e $3^{\circ}$ da Constituição de 1988).

\section{O Direito à Educação como um Direito Fundamental}

Segundo a Constituição de 1988, a educação é um direito fundamental (art. $6^{\circ}$, caput). É competência comum, de União, Estados, Municípios e Distrito Federal "proporcionar os meios de acesso à cultura, à educação e à ciência" (art. 23, V). Já no Capítulo próprio sobre a educação, a Constituição prevê:

Art. 205. A educação, direito de todos e dever do Estado e da família, será promovida e incentivada com a colaboração da sociedade, visando ao pleno desenvolvimento da pessoa, seu preparo para o exercício da cidadania e sua qualificação para o trabalho.

Art. 206. O ensino será ministrado com base nos seguintes princípios: I - igualdade de condições para o acesso e permanência na escola;

II - liberdade de aprender, ensinar, pesquisar e divulgar o pensamento, a arte e o saber;

III - pluralismo de ideias [...];

$[\ldots]$

Art. 208 [...]

$\S 1^{\circ}$ - $\mathrm{O}$ acesso ao ensino obrigatório e gratuito é direito público subjetivo (grifos nossos).

Há também Documentos Internacionais sobre o tema a que o Brasil está vinculado. A Convenção da Conferência Geral da UNESCO relativa à Luta contra a Discriminação no Campo do Ensino (aprovada pelo Legislativo Brasileiro - Decreto $n^{\circ}$ 63.223/68) dispõe: 
Artigo I.

Para os fins da presente Convenção, o termo "discriminação" abarca qualquer distinção, exclusão, limitação ou preferência que, por motivo de raça, cor, sexo, língua, religião, opinião pública ou qualquer outra opinião, origem nacional ou social, condição econômica ou nascimento, tenha por objeto ou efeito destruir ou alterar a igualdade de tratamento em matéria de ensino, e, principalmente:

a) privar qualquer pessoa ou grupo de pessoas do acesso aos diversos tipos ou graus de ensino;

b) limitar a nível inferior à educação de qualquer pessoa ou grupo; [...]

d) de impor a qualquer pessoa ou grupo de pessoas condições incompatíveis com a dignidade do homem.

$[\ldots]$

Artigo III

A fim de eliminar e prevenir qualquer discriminação no sentido da presente Convenção, os Estados partes se comprometem a:

a) ab-rogar quaisquer disposições legislativas e administrativas e fazer cessar quaisquer práticas administrativas que envolvam discriminação;

b) tomar as medidas necessárias, inclusive legislativas, para que não haja discriminação na admissão de alunos nos estabelecimentos de ensino;

[...]

d) não admitir, na ajuda que, eventualmente, e, sob qualquer forma, for concedida pelas autoridades públicas aos estabelecimentos de ensino, nenhuma preferência ou restrição baseadas unicamente no fato de que os alunos pertençam a determinado grupo;

$[\ldots]$

Artigo V

Os Estados-partes, na presente convenção, convêm que:

a) a educação deve visar ao pleno desenvolvimento da personalidade humana e ao fortalecimento do respeito aos direitos humanos e das liberdades fundamentais e que deve favorecer a compreensão, a tolerância e a amizade entre todas as nações... (grifos nossos).

Em sentido semelhante o Pacto Internacional dos Direitos Econômicos, Sociais e Culturais (1966) - ratificado pelo Brasil em 1992: 
Artigo $13, \S 1^{\circ}$. [...] Concordam ainda que a educação deverá capacitar todas as pessoas a participar efetivamente de uma sociedade livre, favorecer a compreensão, a tolerância e a amizade entre todas as nações ... (grifos nossos).

Ainda, na Cúpula Mundial de Educação de Dakar (2000) ficou declarado:

\begin{abstract}
Nós reafirmamos a visão da Declaração Mundial de Educação Para Todos (Jomtien, 1990), apoiada pela Declaração Universal de Direitos Humanos e pela Convenção sobre os Direitos da Criança [art. 29, I], de que toda criança, jovem e adulto têm o direito humano de se beneficiar de uma educação que satisfaça suas necessidades básicas de aprendizagem, no melhor e mais pleno sentido do termo, e que inclua aprender a aprender, a fazer, a conviver e a ser. É uma educação que se destina a captar os talentos e potencial de cada pessoa e desenvolver a personalidade dos educandos para que possam melhorar suas vidas e transformar suas sociedades (grifos nossos).
\end{abstract}

É importante destacar que a Convenção sobre a proteção e promoção da diversidade das expressões culturais (PARIS, 2005) $)^{4}$ deixou claro que o fato de os Direitos Humanos Internacionais protegerem e valorizarem a diversidade cultural, os povos não podem querer se escorar em particularidades culturais ou regionais para ofender outros direitos fundamentais internacionalmente reconhecidos (ver art. Art. 2.1.).

Apesar dos Documentos Internacionais relacionados à educação não correlacionarem, textualmente, esta com a proteção e promoção de direitos dos LGBT, o Governo Brasileiro elegeu a educação como importante ferramenta de superação do preconceito e da violência contra aquela minoria.

A atual Lei de Diretrizes e Bases da Educação (LDB), lei nº 9.394/96: garante o direito à escola a todas as pessoas, sem discriminação (art. $3^{\circ}, \mathrm{IV}$ ). Nela ficou prevista a edição de um Plano Nacional de Educação (art. $9^{\circ}$, I), consubstanciado na lei $\mathrm{n}^{\circ} 10.172 / 01$; essa lei, entretanto, nada falou sobre a questão de gênero.

O Programa Nacional de Direitos Humanos de 2002 (PNDH - II) ressaltou entre as metas do Governo um Capítulo específico para a população LGBT, prevendo, entre outras medidas:

4 Essa Convenção foi ratificada no Brasil pelo Decreto Legislativo n. 485/2006. 
242. Apoiar programas de capacitação de profissionais de educação, policiais, juízes e operadores do direto em geral para promover a compreensão e a consciência ética sobre as diferenças individuais e a eliminação dos estereótipos depreciativos com relação aos GLTTB.

(...)

246. Incentivar programas de orientação familiar e escolar para a resolução de conflitos relacionados à livre orientação sexual, com o objetivo de prevenir atitudes hostis e violentas. (BRASIL, 2002).

O Plano Plurianual 2004-2007 dá seguimento ao Programa Nacional e prevê como ação a Elaboração do Plano de Combate à Discriminação contra Homossexuais. Assim, em 2004. o Governo Federal lançou o Programa "Brasil sem Homofobia", que pretendeu criar um fórum de debates para formulação de políticas públicas. Nesse sentido, a Cartilha "Brasil sem Homofobia" (BRASIL, 2004) traça metas de formulação de políticas públicas a serem buscadas nas mais diversas áreas ${ }^{5}$. No Programa de Ações, o programa Brasil sem Homofobia prevê, no Capítulo V - "Direito à Educação: promovendo valores de respeito à paz e à não discriminação por orientação sexual”. A proposta 23 trata especificamente de políticas de superação da homofobia na escola e da promoção desta em veículo reprodutor de cidadania (cf. BRASIL, 2004, p. 22-23).

O Comitê Nacional de Educação e Direitos Humanos, que elaborou o Plano Nacional de Educação em Direitos Humanos, deixa clara sua concepção acerca dos objetivos do ensino fundamental:

b) a escola, como espaço privilegiado para a construção e consolidação da cultura de direitos humanos, deve assegurar que os objetivos e as práticas a serem adotados sejam coerentes com os valores e princípios da educação em direitos humanos;

$[\ldots]$

d) a educação em direitos humanos deve estruturar-se na diversidade cultural e ambiental, garantindo a cidadania, o acesso ao ensino, permanência e conclusão, a equidade (étnico-racial, religiosa, cultural, territorial, físico-individual, geracional, de gênero, de orientação sexual, de opção política, de nacionalidade, dentre outras) e a qualidade da educação (BRASIL, 2007, p. 32, grifos nossos).

5 No âmbito da educação, destaque para a edição n. 4 dos Cadernos SECAD, que trata da questão do reconhecimento da diversidade sexual na escola (HENRIQUES, 2007) e a Cartilha “Diversidade Sexual na Escola", elaborada pela UFRJ (BORTOLINI, 2008). 
A partir disso, como uma das ações programáticas para a Educação Básica, o Plano Nacional de Educação em Direitos Humanos prescreve:

fomentar a inclusão, no currículo escolar, das temáticas relativas a gênero, identidade de gênero, raça e etnia, religião, orientação sexual, pessoas com deficiências, entre outros, bem como todas as formas de discriminação e violações de direitos, assegurando a formação continuada dos(as) trabalhadores(as) da educação para lidar criticamente com esses temas. (BRASIL, 2007, p. 33) ${ }^{6}$.

Desse conjunto normativo resultam algumas consequências. A não discriminação não é somente um dever "geral" do Estado (e daqueles que, em seu nome atuam), mas, no campo da educação, é um dos particulares deveres da escola - já que, como citado, "a discriminação no [...] ensino constitui violação dos direitos" humanos -, é dizer, a educação ${ }^{7}$ deve se pautar pela promoção das liberdades e direitos assegurados naquelas Declarações, além da Constituição e leis nacionais. Os sistemas de ensino não têm a escolha entre promover ou não os Direitos Humanos e, particularmente aqui, a tolerância.

Dakar (2000) aponta para uma educação que não se limita ao aprendizado, mas que constitua competências e habilidades, isto é, que o aluno "aprenda a aprender, [aprenda] a fazer, [aprenda] a conviver e [aprenda] a ser". A exclusão da escola (seja diretamente, seja pelo abuso, seja omissão frente ao abuso), submetendo o educando a "condições incompatíveis com a dignidade" do ser humano viola seu direito de não ser privado do acesso a quaisquer graus de ensino.

Quanto às diretivas internas, o Estado Brasileiro, nos diversos graus da federação, se comprometeu a realizar programas de capacitação para profissionais da educação (e de orientação familiar) acerca da questão da "orientação sexual" de forma a promover cidadania e prevenir violência.

De sorte que cabe perguntar: será que a escola, em consonância com os compromissos externos e internos que o País assumiu, tem possibilitado uma ambiente educacional que "capte os talentos" e o "potencial de cada pessoa", de acordo com suas personalidades de modo que estes melhorem suas vidas e transformem as sociedades?

6 De forma semelhante, para o Ensino Superior: “desenvolver políticas estratégicas de ação afirmativa nas Instituições de Ensino Superior (IES) que possibilitem a inclusão, o acesso e a permanência de pessoas com deficiência e aquelas alvo de discriminação por motivo de gênero, de orientação sexual e religiosa, entre outros e seguimentos geracionais e étnico-raciais" (BRASIL, 2007, p. 41).

7 No seu sentido mais amplo, isto é, que não se limita às atividades "formais" da escola. 


\section{Por que uma abordagem na escola para os homossexuais?}

É improvável senão quase impossível, nos tempos atuais, até mesmo para o censo comum, não perceber a vultosa emergência de uma "comunidade homossexual" (MOTT, 1997). Mais que um fenômeno de ordem individual, os homossexuais vêm se consolidando como um grupo cultural, uma microcultura que exerce um forte e crescente impacto sobre as relações sociais tradicionais.

Segundo Henriques et. al (2007, p. 33), a escola deve estar à altura dos desafios postos pelas grandes transformações sociais pelas quais estamos passando, garantindo, no mínimo, segurança a grupos marginalizados ${ }^{8}$ Igualmente, quando, aqui, se enfatiza o papel da escola como ambiente igualador ou compensador por ele próprio das diferenças culturais, respeitando e protegendo as minorias ideológicas, faz-se extremamente necessário destacar que por detrás dessas concepções, se ergue a ideia de que as culturas minoritárias, apesar de diferentes, são iguais (BAHIA; NUNES, 2009). Importa perceber que o que se propõe aqui não é mera tolerância, mas reconhecimento, é dizer, não basta aqui que a escola suporte este aluno (pseudo) diferente, mas sim que efetiva e positivamente o reconheça, em sua identidade, em sua diferença. De forma que a tolerância que imponha que o homossexual não incomode os outros, ou seja, desde que "não pareça ser" também é uma forma de violência, já que, se não se permite ser, logo, todos os demais direitos fundamentais estão comprometidos.

Obrigar um aluno ou aluna a modificar o seu jeito íntimo de ser, de falar, de se fazer bonito para poder estudar, é condicionar um direito que é incondicional. É abuso de poder. É desrespeito. E é sinal de que o educador ainda não entendeu que a identidade sexual daquele aluno não é uma firula ou uma brincadeira, mas parte constitutiva da sua própria personalidade (BORTOLINI, 2008).

8 Até porque há relação direta entre menor preconceito e maior escolaridade: “[o] percentual dos jovens que cursaram até a $4^{\mathrm{a}}$ série do Ensino Fundamental e não querem homossexuais como seus vizinhos é de $68,3 \%$, contra $19,1 \%$ daqueles com Ensino Superior. Da mesma forma, apenas $18,8 \%$ dos menos escolarizados são neutros, número muito inferior a indiferença dos $50,1 \%$ dos entrevistados com Ensino Superior" (CARA; GAUTO, 2007, p. 193).

9 Como se pode ver do relato de uma professora: "Dos homossexuais todo mundo sabia, mas eles não pareciam, então não tinha problema” (BORTOLINI, 2008). 
Mais ainda, atitudes assim violam a dignidade da pessoa humana, princípio fundamental da República Federativa do Brasil e o direito de igualdade - concebido em sua dimensão de direito à diferença.

Reconhecer essa complexidade que envolve a problemática do pluralismo cultural é o primeiro passo para construção, de fato, de uma educação multicultural e, assim, promotora da democracia.

\begin{abstract}
A escola e, em particular, a sala de aula, é um lugar privilegiado para se promover a cultura de reconhecimento da pluralidade das identidades e dos comportamentos relativos a diferenças. [...] [A] escola torna-se uma referência para o reconhecimento, respeito, acolhimento, diálogo e convívio com a diversidade (HENRIQUES et. al, 2007, p. 9).
\end{abstract}

Há uma ligação estreita entre o processo histórico de construção da ideia de indivíduo e a (re)construção do conceito de sexualidade (ABRAMOVAY et. $a l, 2004$, p. 30). Sendo a escola locus privilegiado desse processo de construção, sobreleva seu peso na composição de indivíduos sexualmente seguros, maduros e tolerantes. Esse momento da descoberta e formação da sexualidade é também o momento de quebra ou de reprodução de padrões sexistas e discriminatórios (HENRIQUES et. al, 2007, p. 26; BORTOLINI, 2008).

De acordo com uma perspectiva histórico-cultural, a sexualidade é uma das dimensões do ser humano que se constrói e aprende como parte integrante do desenvolvimento da personalidade. E, sendo a escola lugar principal para se trabalhar os saberes, as competências e as mudanças de comportamentos, ela representa um contexto favorável e apropriado para o desenvolvimento de atividades educativas emancipatórias, trabalhando nas mais diversas áreas do conhecimento humano.

Dessa forma, mais do que nunca, há de se investir nas questões da educação sexual intencional e nela a diversidade sexual, entendida como um direito a todo cidadão, desmistificando preconceitos e tabus existentes na educação das pessoas. Isto demanda, portanto, estratégias pedagógicas apropriadas, visando à formação continuada do professor.

Não é de hoje que a formação de professores nesse tema vem sendo abordada, porém sabe-se que não é fácil haver um acordo teórico quanto ao que seja uma "educação sexual".

Ademais, pesquisa citada por vários autores lembra que, para a maioria esmagadora dos pais, a escola é um lugar para o ensino da sexualidade (ABRAMOVAY et. al, 2004, p. 33; ALTMANN, 2001, p. 579; BRASIL, 1997b, p. 291). 
Paradoxalmente (?), no entanto, esta parece se manter refratária à demanda no que se refere à prática de currículos formais, o que não quer dizer que a escola, professore ${ }^{10}$ e funcionários, não falem sobre sexo (ABRAMOVAY et. al, 2004, p. 34): todos os dias, na escola ou fora dela, crianças e adolescentes veem manifestações sobre a sexualidade, muitas vezes preconceituosas, e que reforçam estereótipos.

A consciência/clareza da Educação Sexual como um dos temas transversais remete à necessidade de formação específica para os professores para essa abordagem:

É necessário que o educador tenha acesso à formação específica para tratar de sexualidade com crianças e jovens na escola, possibilitando a construção de uma postura profissional e consciente no trato desse tema. Os professores necessitam entrar em contato com suas próprias dificuldades diante do tema, com questões teóricas, leituras e discussões referentes á sexualidade e suas diferentes abordagens: preparar-se para a intervenção prática junto aos alunos e ter acesso a um espaço grupal de produção de conhecimento a partir dessa prática, se possível contando com assessoria especializada. (BRASIL, SEF, 1998, p. 303).

Um tema como a sexualidade, que ainda possui um sem-número de tabus, é manifestado por crianças e adolescentes não apenas de forma inocente e positiva, mas também com gozações e até violência. De um lado, o silêncio recalcado; do outro, o medo de ser diferente e o medo do diferente.

E como a escola normalmente trata isso? Geralmente em aulas de Biologia, em que se explica cientificamente o funcionamento dos órgãos sexuais, forma de reprodução e DST., o que, por óbvio, fica muito aquém da necessidade.

Um grande avanço para criar meios através dos quais diretores de escola e professores pudessem tratar da sexualidade na escola para além da aula de biologia foi o estabelecimento da Orientação Sexual como tema transversal dos Parâmetros Curriculares Nacionais, onde se afirma, entre outras coisas, as necessidades de se:

10 “Os professores [...], mesmo sem perceber, transmitem valores com relação à sexualidade no seu trabalho cotidiano, inclusive na forma de responder ou não às questões mais simples trazidas pelos alunos (BRASIL, 2007b, p. 302-303). Também Henriques (2007, p. 28) anota que pesquisa da UNESCO de 2002, sobre o "Perfil do Professor Brasileiro", mostrou que 59,7\% deles acham inadmissível uma pessoa ter relações homossexuais e $21,2 \%$ não gostariam de ter um vizinho homossexual. 
- respeitar a diversidade de valores, crenças e comportamentos relativos à sexualidade, reconhecendo e respeitando as diferentes formas de atração sexual e o seu direito à expressão, garantida a dignidade do ser humano; $[\ldots]$

- identificar e repensar tabus e preconceitos referentes à sexualidade, evitando comportamentos discriminatórios e intolerantes e analisando criticamente os estereótipos;

- reconhecer as construções culturais, as características socialmente atribuídas ao masculino e ao feminino, posicionando-se contra discriminações a eles associadas;

$[\ldots]$

- [ter] consciência crítica e tomar decisões responsáveis a respeito de sua sexualidade. (BRASI, 1997b, p. 311-312).

A educação sobre orientação sexual é colocada no PCN como tema transversal, isto é, não se insere como disciplina autônoma, por outro lado, deve percorrer diversas disciplinas e a própria atitude do educador frente aos alunos, incluindo temas que não são tratados normalmente do currículo, como: "aborto, virgindade, homossexualidade, pornografia, prostituição e outras" (BRASIL, 1997b, p. 308) ${ }^{11}$. A educação, sendo um direito humano básico, é considerada elemento essencial para realizar as mudanças políticas, sociais e econômicas. A Educação Sexual não foge dessa realidade, uma vez que a escola, enquanto espaço de partilha de conhecimentos, culturas, valores, mudanças e desenvolvimento de competências, pode e deve ser um lugar para Educação Sexual emancipatória intencional. (PEREIRA, 2010, p. 36), e os professores não devem ficar indiferentes a ela, embora se encontrem envolvidos nos limites e possibilidades da estrutura do sistema educacional. Do educador se pede que, vendo que essas são necessidades legítimas dos alunos, estejam abertos a (pelo menos) conversar sobre o tema. Isso poderá contribuir para que os alunos tenham "uma maior consciência de seu próprio corpo, elevação de sua autoestima e, portanto, melhores condições de preservação das doenças sexualmente transmissíveis, gravidez indesejada e abuso sexual" (BRASIL, 1997b, p. 302).

Os Parâmetros Curriculares Nacionais são objeto de críticas no que tange ao Capítulo referente à "Orientação Sexual” (cf. ALTMANN, 2001, p. 581). Sem embargo, ainda constituem um dos marcos mais consistentes quanto às políticas públicas educacionais de tratamento da sexualidade no Brasil (cf. HENRIQUES,

11 Como tema transversal, se pode dizer que a educação em orientação sexual "precisa ser clara, para que seja tratada de forma simples e direta; ampla, para não reduzir sua complexidade, flexível, para permitir o atendimento a conteúdos e situações diversas; e sistemática, para possibilitar aprendizagem e desenvolvimento crescentes" (BRASIL, 1997b, p. 307, grifos nossos). 
2007, p. 12), ainda que, passados mais de dez anos de sua ediçãopouco do que ali esteve previsto tenha sido colocado em prática nas escolas.

Um passo adiante no ensino sobre diversidade sexual na escola foi dado em 2004, quando, a partir do citado programa "Brasil sem Homofobia" é criada a SECAD - Secretaria de Educação Continuada, Alfabetização e Diversidade. Entre as ações da SECAD, destaque para a Rede (Rede de Educação para a Diversidade) - grupo de IES públicas que promove cursos de capacitação de professores e profissionais de educação em temas sobre diversidade -; a Educação em Direitos Humanos, entre outros. Das ações da SECAD surgiram trabalhos de orientação e capacitação de professores e profissionais da educação, em linguagem simples e direta, a respeito de como a escola deve lidar com a diversidade sexual. Entre estes trabalhos está a Cartilha Diversidade Sexual na Escola (BORTOLINI, 2008), elaborada por professores da UFRJ. Essa Cartilha mostra que, não sendo a homossexualidade uma doença, não se cabe a designação homossexualismo ${ }^{12}$. Anota que construções sobre o que é ser mulher e homem são mais produtos sociais do que determinantes biológicas, o que enfraquece argumentos que justificam preconceitos e diferenças de gênero a partir de pseudonaturalismos. Ao mesmo tempo, desmistifica padrões sobre o que é ser homem e o que é a masculinidade, questões muito importantes quando se trata de violência e discriminação dos que não se encaixam. Especificamente quanto à homossexualidade, explica o que é e quais são as orientações sexuais e identidades de gênero. Além disso, desconstrói alguns equívocos: de se achar que a homossexualidade seja uma "escolha", de que haja maior incidência de AIDS entre eles, ou que homossexuais sejam mais "promíscuos" ou ainda que tenham mais dificuldade de ter relações estáveis. Aborda questões mais prosaicas como se pensar que a sensibilidade seja algo ligado necessariamente ao gay, ou que alguém é mais gay porque passivo em relações sexuais.

Dirigindo-se aos professores a Cartilha dá ainda algumas dicas sobre qual deve ser sua atitude: não podem agir a partir dos seus valores, mas com uma cultura de tolerância. É uma questão de ética profissional, algo mínimo que se espera de um profissional frente a colegas, clientes - frente ao outro enfim -, de outras etnias, credos (cf. BORTOLINI, 2008). De fato, em uma sociedade democrática e plúrima, não há outra alternativa: não se pede que ele seja menos intolerante, exige-se que deixe de ser intolerante (HABERMAS, 2003 p, 12).

12 O termo "homossexualismo" foi utilizado até 1985 pela Classificação Internacional de Doenças, publicação da Organização Mundial da Saúde, na qual era descrita na categoria de distúrbio mental. 


\section{Homofobia na Escola}

A escola não é um ambiente separado do meio social. Não se trata aqui de um "lugar do conhecimento e da reflexão" imune às vicissitudes e problemas da sociedade. Antes pelo contrário, participa e está inserida, para o melhor e para o pior.

No campo da sexualidade não é diferente. Ainda que a escola se silencie (ou melhor, justamente por isso), o aprendizado e a (de)formação ocorrem também nesse espaço, que, afinal, se constitui em uma das principais arenas de convivência e sociabilidade da criança e do adolescente. Esse pode ser um tempo de aprendizagem com o respeito às diferenças de gênero e de orientação sexual ou, como já dito, apenas de reprodução de padrões discriminatórios. Igualmente, Junqueira (2007, p. 64) afirma que:

a sexualidade é vista a partir do risco e da ameaça. Faz-se, com frequência, na escola, um discurso repressivo, centrado na medicalização, no medo, na "naturalização da heterossexualidade", na "heterossexualização compulsória", na propaganda da conjugalidade heterossexual e à revelia do conhecimento científico.

Pelo que vimos com os documentos normativos (nacionais e internacionais), a escola já possui sua opção escolhida. A realidade, por outro lado, é bem outra. Em uma pesquisa feita na Parada do Orgulho LGBT do Rio de Janeiro, " $40 \%$ dos adolescentes homossexuais entrevistados contaram já haver sofrido casos de discriminação dentro da Escola. Entre jovens de 19 a 21 anos, 31\% se referiram a discriminações na escola ou na faculdade" (BORTOLINI, 2008). A escola seria o terceiro lugar onde eles mais sofrem(ram) discriminação.

O preconceito na escola mostra a reprodução de padrões de pseudonormalidade acerca dos papéis de gênero, nos quais a masculinidade ainda é alçada à condição de superioridade. Nesse sentido, compartilhamos o entendimento segundo o qual sociedades machistas tendem a ser também homofóbicas, pois que, ao hipostaziar papéis de gênero, enxergam a homossexualidade como um desvio, e.g., no caso do homossexual masculino, ter-se-ia a desconcertante situação de um homem que se "rebaixa" à situação de uma mulher. A falta de uma educação cidadã na escola estimula (ou, ao menos, não impede) a reprodução de padrões de masculinidade calcados no "apelo à agressão física e subordinação, discriminação contra mulheres e contra o homoerotismo" (ABRAMOVAY, 2005, p. 75). 
A pesquisa coordenada por Abramovay, publicada em 2004, envolveu estudantes do ensino fundamental e médio de trezes capitais de Estados e o Distrito Federal e contém um retrato vívido sobre a sexualidade dos jovens brasileiros da atualidade. Entre os dados, há indícios muito auspiciosos: mais de $80 \%$ dos alunos não acham que a homossexualidade seja uma doença. Quando se projetam os dados frente à idade, vê-se que, quanto mais tenra a idade, menor a percepção da homossexualidade como uma doença. Entre os professores a porcentagem é pouco menor do que entre os alunos, mas tanto professores quanto pais reconhecem, na maior parte, que não têm conhecimentos suficientes sobre a questão (ABRAMOVAY et. al, 2004, p. 293-294). Mas há muitos dados preocupantes. Quanto à percepção dos estudantes quanto aos tipos de violência. Há quase sempre uma coincidência sobre o que homens e mulheres consideram mais ou menos violento, com uma exceção: para as mulheres, "bater em homossexuais" é a terceira maior violência, enquanto que para os rapazes, é a apenas a sexta. Outrossim, os homens admitem, com muito mais facilidade a discriminação contra homossexuais do que por raça ou sexo. Quando se pergunta "quem eles não queriam ter como colegas", 1/4 diz homossexuais. Entre homens os dados são mais significativos. Mas, são ainda maiores os índices de pais que não querem que seus filhos sejam colegas de homossexuais. O preconceito é gerado pelo outro (objeto do preconceito), "que assim é culpado de algo que não se sabe bem o que, o que tornam todos [preconceituoso e vítima] impotentes" (ABRAMOVAY et. al, 2004, p. 279-283).

Ao se falar em violência, não se trata somente da violência física, mas também simbólica. O uso de palavras pejorativas é algo especialmente problemático quando isso se dá no ambiente da escola.

A pesquisa ainda mostra que os professores admitem ter pouco conhecimento sobre a homossexualidade (o que abre a "deixa" para políticas públicas de esclarecimento) e isso se reflete nas respostas que eles deram aos questionamentos. Também entre eles, boa parte não gostaria de ter um homossexual como vizinho; em geral, eles "minimizam" os efeitos danosos de "brincadeiras" discriminatórias feitas pelos alunos (ou simplesmente se calam). O que se percebe é que eles, em geral, não sabem lidar com a situação, por vezes reforçam o preconceito (que até querem combater).

Entre os homossexuais um capítulo específico sobre a discriminação deve ser dado aos indivíduos travestis e transexuais: minorias mais afetadas pela discriminação pessoal (tanto por parte dos alunos, mas também por professores) e institucional (na medida em que não lhes são dadas condições mínimas de respeito quanto à sua identidade); em razão disso, possuem, outrossim, os maiores índices de abandono escolar (cf. HENRIQUES, 2007, p. 28; BORTOLINI, 2008). 


\section{Considerações finais}

É certo que a sexualidade humana figura como um dos temas mais inquietantes e, quase sempre, mais recusados na ação prática do professor. Entretanto, cada vez mais a escola tem sido convocada a enfrentar as transformações das práticas sexuais contemporâneas, uma vez que seus efeitos se fazem alardear no cotidiano escolar. Assim, para uma educação sexual é essencial que os indivíduos participem eficazmente, tomem decisões e tenham direito à voz, o que exige uma educação democrática e acesso à informação.

Percebe-se que existe uma quantidade considerável de instrumentos normativos (internacionais e nacionais), além de pesquisas e trabalhos sobre o papel dos professores relativamente à Educação Sexual na Escola, porém observa-se que são escassas as escolas que abarcam explicitamente esta temática nas suas práticas pedagógicas. Quando tocam no tema, boa parte se limita a ações informativas a cargo de diversos profissionais, como se fosse suficiente para elucidar as interrogações confrontadas com a sexualidade humana e as suas variadas expressões. Por todo o exposto, percebe-se que isso não é suficiente se se quer superar o quadro social sexista, homoófico e misógino que vivenciamos ${ }^{13}$.

Com o surgimento do HIV/AIDS e o seu alastramento por todo o mundo, as preocupações acabaram por se intensificar, exigindo do poder público medidas imediatas de implantação, manutenção e/ou alargamento de programas educativos de prevenção à AIDS nas redes públicas e privadas de ensino em todos os níveis. Neste movimento, sublinhar a questão do Direito fundamental à Educação, a Diversidade e a Homofobia na Escola especificamente visando à construção de um ambiente de aprendizado livre, plural e democrático, não é fácil. Contudo, propor a reflexão sobre a temática em questão, é fundamental nos dias de hoje, visto que a realidade atual nos confronta com a diversidade sexual e, conseqüentemente com a homofobia em nossas salas de aula. A criança e/ou adolescente é sujeita a preconceitos de todos os tipos. Infelizmente, sabese que grande parte deste preconceito, desta discriminação é conseqüência dos padrões sócio-culturais estereotipados sobre as questões que envolvem este tema. Por isso há necessidade de propostas educativas como forma de prevenção à homofobia e de combate à discriminação das pessoas LGBT. Cabe ressaltar que o reconhecimento pelos professores da necessidade de abordagem da diversidade sexual é o primeiro passo. Porém, sabe-se que é preciso uma mudança de

13 Não desconsideramos que há experiências muito ricas, mas isoladas, de educadores e escolas que vêm conseguindo aquele objetivo, se valendo dos mais variados instrumentos lúdicos, audiovisuais etc. 
comportamento e atitudes por parte de todo o sistema educacional e que esta demandará de tempo, devido às posturas e às condutas adotadas histórica e culturalmente na nossa sociedade. E, ainda, o sentido para o modelo reflexivo de formação, proposto por vários autores - contínuo, longo e sistemático, em que sejam enaltecidas as experiências, as histórias de vida, as práticas pedagógicas, os saberes construídos pelos professores, o exercício de reflexão em grupo e o desenvolvimento de competências para abordar este assunto.

\section{REFERÊNCIAS}

ABRAMOVAY, M.; CASTRO, M.; SILVA L. Juventude e sexualidade. Brasília: UNESCO Brasil, 2004.

ABRAMOVAY, M. (Coord.). Cotidiano das escolas: entre violências. Brasília: UNESCO; Observatório de Violência; Ministério da Educação, 2005.

ALTMANN, H. Orientação Sexual nos Parâmetros Curriculares Nacionais. Revista Estudos Feministas, Florianópolis, ano 9, p. 575-585, $2^{\circ}$ semestre 2001.

BAHIA, A.; NUNES, D. O potencial transformador dos direitos privados no constitucionalismo pós-88. Revista dos Tribunais, São Paulo, v. 882, p. 45-60, abril de 2009.

BORTOLINI, A. (Coord.). Diversidade Sexual na Escola. Rio de Janeiro: Pró-Reitoria de Extensão/UFRJ, 2008.

BRASIL. Ministério da Educação. Secretaria de Educação Fundamental. Parâmetros curriculares nacionais: pluralidade cultural, orientação sexual. Brasília: MEC/SEF, 1997a.

BRASIL. Ministério da Educação. Secretaria de Educação Básica. Parâmetros curriculares nacionais: Orientação Sexual. Brasília: MEC/SEB, 1997b. Acesso em: 25/5/2009.

BRASIL. Ministério da Justiça. Secretaria de Estado dos Direitos Humanos. Programa Nacional de Direitos Humanos - PNDH II. Brasília, 2002.

BRASIL. Conselho Nacional de Combate à Discriminação. Ministério da Saúde. Brasil Sem Homofobia : Programa de Combate à Violência e à Discriminação contra GLTB e Promoção da Cidadania Homossexual. Brasília: Ministério da Saúde, 2004. 
BRASIL. Comitê Nacional de Educação em Direitos Humanos. Plano Nacional de Educação em Direitos Humanos. Brasília: Secretaria Especial dos Direitos Humanos. Brasília: MEC, Ministério da Justiça, UNESCO, 2007.

CARA D.; GAUTO, M. Juventude: percepções e exposição à violência. In: ABRAMOVAY, M.; ANDRADE, E.; ESTEVES, L. Juventudes: outros olhares sobre a diversidade. Brasília: Ministério da Educação, Secretaria de Educação Continuada, Alfabetização e Diversidade; UNESCO, 2007, p. 171-196.

CARVALHO NETTO, M. A Constituição da Europa. In: SAMPAIO, J. (Coord.). Crise e Desafios da Constituição. Belo Horizonte: Del Rey, 2004. p. 281-289.

DAKAR. Cúpula Mundial de Educação. Dakar, Senegal. 26 a 28 de abril de 2000. Disponível em: <http://www.mp.ma.gov.br/site/centrosapoio/DirHumanos/decDakar. $\mathrm{htm}>$. Acesso em: 23/10/2010.

GARRIDO, E.; PIMENTA, S.; MOURA, M. A pesquisa colaborativa na escola como abordagem facilitadora para o desenvolvimento da profissão de professor. In: MARIN, A. J. (Org.). Educação continuada. Campinas: Papirus, 2000.

HABERMAS, J. Sobre el Concepto y Papel de la Tolerancia Religiosa en Sociedades Occidentales. Revista Diálogo Científico, Tubigen, v. 12, n. 12, p. 11-22, 2003.

HENRIQUES, R. et al. (Org.). Gênero e Diversidade Sexual na Escola: reconhecer diferenças e superar preconceitos. Cadernos SECAD, n. 4, Brasília, maio de 2007.

JUNQUEIRA, R. O reconhecimento da diversidade sexual e a problematização da homofobia no contexto escolar. In: RIBEIRO, P. et. al. (Orgs.). Corpo, Gênero e Sexualidade: Discutindo práticas educativas. Rio Grande: FURG, 2007. p. 59-69.

MOTT, L. Homofobia: a violação dos direitos humanos de gays, lésbicas e travestis no Brasil. Comissão Internacional de Direitos Humanos de Gays e Lésbicas. São Francisco, Califórnia: 1997.

PARIS. Convenção sobre a proteção e promoção da diversidade das expressões culturais, UNESCO. Paris, França, 03 a 21 de outubro de 2005. Disponível em: $<$ http:// unesdoc.unesco.org/images/0015/001502/150224por.pdf $>$. Acesso em: 20/10/2010.

PEREIRA, G. R. Decursos Educativos e Conhecimentos para uma Educação Sexual Emancipatória Intencional. Revista Linhas, v. 11, n.1, p. 36-52, 2010.

PIOVESAN, F. Igualdade, diferença e direitos humanos: perspectivas global e regional. In: LEITE, G.; SARLET, I. Direitos Fundamentais e Estados Constitucional: estudos em homenagem a j. j. gomes canotilho. São Paulo: RT/Coimbra: Coimbra Ed., 2009, p. 294-322. 
PRADO, L. Educação para democracia. Rio de Janeiro. Nova Fronteira, 1984.

RIOS, R. A homossexualidade e a discriminação por orientação sexual no direito brasileiro. Revista de Informação Legislativa, Brasília, ano, 38, n. 149, p. 279-295, jan./mar. 2001.

Texto recebido em junho de 2010.

Texto aprovado em outubro de 2010. 